\title{
Effect of seasonal changes on fertility parameters of Holstein dairy cows in subtropical climate of Taiwan
}

\author{
Wen-Bor Liu ${ }^{1,2}$, Huo-Cheng Peh ${ }^{1}$, Chien-Kai Wang ${ }^{1}$, Mancoba Christopher Mangwe ${ }^{1,3}$, \\ Chih-Feng Chen ${ }^{1,2,4,5}$, and Hsin-I Chiang ${ }^{1,2,6, *}$
}

* Corresponding Author: Hsin-I Chiang
Tel: +886-4-2287-0613, Fax: +886-4-2286-0265,
E-mail: samchiang@nchu.edu.tw

${ }^{1}$ Department of Animal Science, National Chung Hsing University, Taichung 402, Taiwan

2 Experimental Animal Farm, National Chung Hsing University, Taichung 402, Taiwan

${ }^{3}$ Faculty of Agriculture and Life Science, Department of Agricultural Science, Lincoln University, Lincoln

7647, New Zealand

${ }^{4}$ Center for integrative Evolutionary Galliforms Genomics Research (iEGG Center), National Chung Hsing University, Taichung 402, Taiwan

${ }^{5}$ The iEGG and Animal Biotechnology Center, National Chung Hsing University, Taichung 402, Taiwan

${ }^{6}$ International Agriculture Center, National Chung

Hsing University, Taichung 402, Taiwan

ORCID

Wen-Bor Liu

https://orcid.org/0000-0002-3185-0468

Huo-Cheng Peh

https://orcid.org/0000-0002-2473-4768

Chien-Kai Wang

https://orcid.org/0000-0002-9162-6820

Mancoba Christopher Mangwe

https://orcid.org/0000-0002-7533-1889

Chih-Feng Chen

https://orcid.org/0000-0002-3976-5743

Hsin-I Chiang

https://orcid.org/0000-0002-2815-4314

Submitted Apr 18, 2017; Revised Jul 1, 2017; Accepted Sept 11, 2017
Objective: The purpose of this retrospective study was to investigate the relationship between temperature-humidity index (THI), season, and conception rate (CR) of Holstein cows in central Taiwan.

Methods: The mean performance and number of observations were statistically evaluated for various parameters, including age at first service, number of days open, gestation length, $\mathrm{CR}$, and calving interval for different parities.

Results: The results indicate that the mean age at first service was 493.2 days; the gestation length was similar across all cows of different parities, ranging from 275.1 to 280.7 days. The overall CR of all inseminations was significantly lower in multiparous cows $(47.26 \% \pm 0.22 \%)$ than in heifers $(57.14 \% \pm 0.11 \%)(\mathrm{p}<0.05)$. At THI $>72$ and during the hot season (from June to November), CRs for multiparous cows were significantly reduced compared to that for heifers, while the ratio remained unchanged among heifers for all seasons.

Conclusion: To achieve a high CR, lactating cows should be bred in winter and spring (from December to May) from the start of the seasonal breeding program, whereas the heifer should be allowed to breed in summer and fall under the subtropical climate in Taiwan.

Keywords: Calving Interval; Dairy Cow; Fertility; Temperature-humidity Index; Heat Stress

\section{INTRODUCTION}

The economic return from individual cows is represented by the integration of several performance traits besides milk production. Specific traits such as the age at first service, age at first calving (AFC), number of days open, gestation length, conception rate (CR; pregnancy per artificial insemination (AI) service), calving interval for different parities, and length of herd life are important factors contributing to economic return and are partially determined by management policies. Lactating dairy cows prefer ambient temperatures (ATs) between $-5^{\circ} \mathrm{C}$ and $25^{\circ} \mathrm{C}$, which is known as the thermoneutral zone. Above this temperature, cows can no longer adequately cool themselves and experience heat stress [1]. Milk production leads to metabolic heat production because of the metabolism of large amounts of nutrients; thus, cows with high milk productivity are more vulnerable to heat stress compared to those with lower yields [2]. Heat stress, which is caused by a combination of seasonal influences such as air temperature, relative humidity (RH), solar radiation, and wind speed, depresses milk production and reproduction performance in lactating cows [3]. Heat stress is the main environmental factor responsible for the lower fertility of cattle, especially during the summer season in many warm areas of the world [4]. This worldwide problem inflicts considerable economic losses and affects about $60 \%$ of the world's cattle population [5]. For the US dairy industry, annual economic losses caused by heat stress alone have been estimated to be about 
$\$ 900$ million [6]. The climate of central Taiwan is defined as subtropical with concentrated rainfall during the hot season. Summers in Taiwan are extremely hot and humid, with temperatures and $\mathrm{RH}$ often exceeding $30^{\circ} \mathrm{C}$ (above $85^{\circ} \mathrm{F}$ ) and $80 \%$ from June to November. Even though the environmental conditions suggest the possibility of the presence of heat stress, there has been no assessment of the influence of heat stress on the fertility of dairy cows in central Taiwan. The knowledge of these factors will make it easy to establish corrective measures to attain better fertility. In addition, AFC plays a critical role in achieving high profitability in dairy enterprises. Rearing replacement heifers needs large financial expenditure with no returns until the animals enter the milking herd [7]. An earlier AFC can save rearing costs due to decreased feed, labor fee, and rearing space. A previous study showed that reducing AFC from 25 months to 24 or 21 months could reduce rearing costs by $4.3 \%$ or $18 \%$, respectively [7]. To maximize lactation performance and to reduce rearing costs, the mean AFC in Holstein heifers is recommended to be $\leq 24$ months of age with a body weight of $<560 \mathrm{~kg}$ [8]. A majority of dairy producers in the United Kingdom aim to start breeding Holstein Friesian heifers from around 14 to 15 months of age, and thus, the target AFC is generally 24 months on their farms [7]. No similar investigation has been conducted in central Taiwan. Therefore, the objective of the present study was to evaluate the effects of temperature, $\mathrm{RH}$, and temperature-humidity index (THI) on the reproductive performance (AFC, number of days open, gestation length, $\mathrm{CR}$, and calving interval) in Holstein cows of different parities. These results will help establish a management guide for dairy cattle in a subtropical region similar to central Taiwan.

\section{MATERIALS AND METHODS}

\section{Animal housing and management}

This study was conducted at the National Chung Hsing University (NCHU) Experimental Animal Farm in Taiwan (latitude and longitude is $24^{\circ} 04^{\prime} \mathrm{N}$ and $120^{\circ} 38^{\prime} \mathrm{W}$, respectively). The herd consisted of Holstein heifers and cows, and the herd size was maintained at less than 110 animals. Animal health care was under the veterinary supervision. The animals were housed in groups in free-stall barns with slatted floors bedded with sand and equipped with overhead fans and a sprinkler system. Access to a shaded outdoor-exercise yard was also available for all lactating cows. Throughout the experimental period (from 2001 to 2013), cows were milked and fed twice daily with a diet of total mixed ration consisting of corn silage, sweet oats, chopped alfalfa, and Bermuda grass hay, as well as concentrate, minerals, and vitamins for lactating cows (Table 1). Fresh water was provided ad libitum. The mean milk yield for the herd was $8,700 \mathrm{~kg}$ for 305 days of lactation. The studied lactating cows (weighing $613 \mathrm{~kg}$ in average) were ranged from 2 year to 11
Table 1. Composition of concentrate mixtures fed to cows

\begin{tabular}{lcc}
\hline Ingredients & Lactating cows $(\mathbf{k g})$ & Dry cows $(\mathbf{k g})$ \\
\hline Corn & 470.00 & 708.00 \\
Soybean meal & 150.00 & 185.00 \\
Full-fat soy flour & 80.00 & 0.00 \\
Fish meal & 50.00 & 0.00 \\
Bran & 120.00 & 50.00 \\
Calcium carbonate & 12.00 & 11.00 \\
Dicalcium phosphate & 4.00 & 10.00 \\
Molasses & 40.00 & 20.00 \\
Salt & 8.00 & 10.00 \\
Saponification of fat powder & 50.00 & 0.00 \\
Sodium bicarbonate & 13.00 & 0.00 \\
Vitamins $^{1)}$ & 1.00 & 2.00 \\
Minerals $^{2)}$ & 2.00 & 4.00 \\
Total $^{2}$ & $1,000.00$ & $1,000.00$ \\
\hline
\end{tabular}

1) Vitamin premix formula: vitamin $A, 16,000,000 \mathrm{IU}$; vitamin $\mathrm{D}_{3}, 6,000,000 \mathrm{IU}$; and vitamin $\mathrm{E}, 100,000 \mathrm{mg}$. The vitamin content (vitamins $\mathrm{A}, \mathrm{D}$, and $\mathrm{E}$ ) was no lower than 1.5 times of the National Research Council (NRC [18]) recommended content.

${ }^{2)}$ Mineral premix formula (per $\mathrm{kg}$ ): ferrous sulfate, $60.00 \mathrm{~g}$; manganese sulfate, $50.00 \mathrm{~g}$; copper sulfate, $12.50 \mathrm{~g}$; sodium selenite, $0.40 \mathrm{~g}$; zinc sulfate, $50.00 \mathrm{~g}$; and cobalt carbonate, $0.15 \mathrm{~g}$. The mineral content $(\mathrm{Co}, \mathrm{Cu}, \mathrm{Fe}, \mathrm{Mn}, \mathrm{S}, \mathrm{Se}, \mathrm{Na}$, and $\mathrm{Mg}$ ) was no lower than 1.2 times of the NRC [18] recommended content.

year in age and 1 to 8 in parities. The reproductive assessments included CR, which was the ratio of the number of pregnancies per AI, and parity, which measured the number of births within the total fertility of cows over their reproductive life.

\section{Pregnancy diagnosis}

Pregnancy was confirmed using transrectal real-time ultrasonography 30 days after AI by the herd veterinarians. Pregnancy was verified by the presence of uterine fluid and an embryo with its heartbeat. The dates on which fertile insemination was performed as well as the number of inseminations per conception were recorded. Cows that were observed in estrus more than 10 days after AI were assumed as nonpregnant and reinseminated.

\section{Meteorological data}

Three different heat load indices are related to CR: mean THI, maximum THI, and minimum THI [5]. In this retrospective study, we aimed to investigate the relationship between THI and CR of Holstein cows in central Taiwan. In total, 13-year climatic records (from 2001 to 2013) were obtained from the official meteorological stations of the Taiwan Agricultural Research Institute, Wufeng, Taichung. The monthly and daily maximum temperatures and mean $\mathrm{AT}$ and $\mathrm{RH}$ were recorded throughout the year; the AT and RH data were used to calculate THI using the following equation: $\mathrm{THI}=(1.8 \times \mathrm{AT}+32)$ $-[(0.55-0.0055 \times \mathrm{RH}) \times(1.8 \times \mathrm{AT}-26)][5]$. The official meteorological station is approximately 10-kilometer away from the NCHU Experimental Animal Farm. Average temperatures 
and humidity are similar for the two locations. However, the effects of the artificial cooling system in the barn were not considered in the study.

\section{Statistical analyses}

The date, age, parity, breed of semen-donor bull, season, date of estrus, names of AI technicians, and the time and date of AI were recorded. Raw data were collated using Microsoft Excel (Microsoft Corp., Redmond, WA, USA) and were subsequently transferred to SPSS analytical software (version 11.5; SPSS, Inc., Chicago, IL, USA) for multiple logistic regressions, whereas continuous variables (calving to first service interval, calving to conception interval, THI, CR, and different parities) were evaluated using the analysis of variance (PROC general linear model from SAS). The significance of differences for continuous variables was tested using Tukey's test (least square means statement). Results were considered to be significant at $\mathrm{p}<0.05$.

\section{RESULTS}

\section{The effects of climate changes on fertility}

The dataset contained 1,321 breeding records and associated pregnancy diagnoses from 607 dairy cows. The overall CR obtained was $48.5 \%$. Minimum, maximum, and mean ATs during the study period were $12.2^{\circ} \mathrm{C}, 32.8^{\circ} \mathrm{C}$, and $24.13^{\circ} \mathrm{C}$, respectively, and mean RH during the study period was $80.08 \%$ (Table 2). Minimum, maximum, and mean THIs during the study period were $61.30,80.39$, and 72.19 , respectively. THI showed seasonal fluctuations with lower monthly means (from 66.44 to 70.90) during cold climate conditions (from December to May) and higher monthly means (from 74.93 to 79.75 ) during hot climate conditions (from June to November) as shown in Table 3. Temporal trends of the evaluated THI are shown in Figure 1 . THI was significantly affected by the season, with a monthly variation ranging between 60 and 80, although it did not vary significantly over the years. Table 3 shows that CRs were significantly affected by the seasons, particularly in dairy cows. Hot seasons (from June to November) significantly reduced CRs for multiparous cows $(\mathrm{p}<0.05)$, while CRs in heifers remained unchanged in all seasons. As shown in Table 4 , at THI of $>72$, CR for multiparous cows was significantly
Table 2. Monthly temperatures (mean, $\max$, and $\min ,{ }^{\circ} \mathrm{C}$ ), mean relative humidity (RH \%), and mean temperature-humidity index (TH \%) during the study period (from 2001 to 2013) in central Taiwan

\begin{tabular}{lccccc}
\hline \multirow{2}{*}{ Months } & \multicolumn{3}{c}{ Temperature $\left({ }^{\circ} \mathrm{C}\right)$} & Mean RH & $\begin{array}{c}\text { Mean THI } \\
\%\end{array}$ \\
\cline { 2 - 4 } & Mean & Max & Min & 78.24 & 61.30 \\
\hline Jan. & 17.50 & 22.79 & 12.21 & 78.99 & 63.77 \\
Feb. & 18.97 & 23.83 & 14.10 & 77.82 & 63.56 \\
Mar. & 20.53 & 25.06 & 16.00 & 70.67 & 72.38 \\
Apr. & 24.02 & 28.33 & 19.70 & 80.67 & 76.75 \\
May & 26.60 & 30.75 & 22.45 & 81.44 & 78.96 \\
Jun. & 28.07 & 31.96 & 24.18 & 82.37 & 79.91 \\
Jul. & 28.92 & 32.45 & 25.38 & 80.20 & 80.39 \\
Aug. & 28.89 & 32.81 & 24.97 & 82.08 & 79.22 \\
Sep. & 28.16 & 32.20 & 24.11 & 83.23 & 74.77 \\
Oct. & 25.81 & 30.50 & 21.11 & 79.20 & 70.80 \\
Nov. & 22.62 & 27.15 & 18.08 & 79.27 & 64.45 \\
Dec. & 19.46 & 24.80 & 14.11 & 77.50 & \\
\hline
\end{tabular}

reduced compared to that for heifers $(\mathrm{p}<0.05)$. CRs for multiparous cows were $43.84 \%$ and $50.68 \%$ at THIs of $>72$ and $\leq 72$, respectively, over the 13 -year study. For a $\mathrm{THI}<72$, CR was high throughout the year, with no significant differences between the months or seasons.

\section{Effect of different parities on conception rate, days open and gestation length}

The reproductive efficiency of the herd is important to the economic success of the dairy operation. Table 5 shows that the number of required AI services differed across cows of different parities, where cows in parities 6 and 7 have higher CRs than those in parities $2,3,4,5$, and $8(\mathrm{p}<0.05)$. The overall $\mathrm{CR}$ for all inseminations was significantly lower in multiparous cows $(47.26 \% \pm 0.22 \%)$ than that in heifers $(57.14 \% \pm 0.11 \%)$ $(\mathrm{p}<0.05)$. Table 6 shows the time elapsed for getting pregnant (days open) of Holstein cows with different parities. A larger number of days open indicate a decline in fertility of cows. At the NCHU Experimental Animal Farm. Significant differences in the number of days open were found across between parity 7 to 8 cows and parity 1 to 2 , parity 3 to 4 and parity 5 to 6 , parity 6 to 7 cows. Table 7 shows that the length of the gestation periods varied from 252 days to 304 days across all cows of different parities. Most of the calves were born between the

Table 3. Temperature, mean temperature-humidity index (THI), and seasons associated with conception rates (CR) of heifers and multiparous cows

\begin{tabular}{|c|c|c|c|c|c|c|}
\hline \multirow{2}{*}{ Season } & \multirow{2}{*}{ Mean temperature $\left({ }^{\circ} \mathrm{C}\right)$} & \multirow{2}{*}{ Mean THI } & \multicolumn{2}{|c|}{ Number of animals (N) } & \multicolumn{2}{|c|}{ CR (\%) } \\
\hline & & & Heifers & Multiparous cows & Heifers & Multiparous cows \\
\hline Spring (from Mar. to May) & 23.72 & 70.90 & 30 & 95 & $60.73^{\mathrm{a}}$ & $51.25^{\mathrm{a}}$ \\
\hline Fall (from Sep. to Nov.) & 25.53 & 74.93 & 25 & 118 & $54.26^{a}$ & $43.13^{b}$ \\
\hline Winter (from Dec. to Feb.) & 18.98 & 66.44 & 14 & 126 & $57.41^{\mathrm{a}}$ & $50.66^{\mathrm{a}}$ \\
\hline
\end{tabular}

CR: conception rate (pregnancy per artificial insemination service).

${ }^{a, b}$ Means with different superscripts in the same row differ at $p<0.05$. 
100

- - THI mean $\quad \ldots .$. THI max $\quad$ THI min

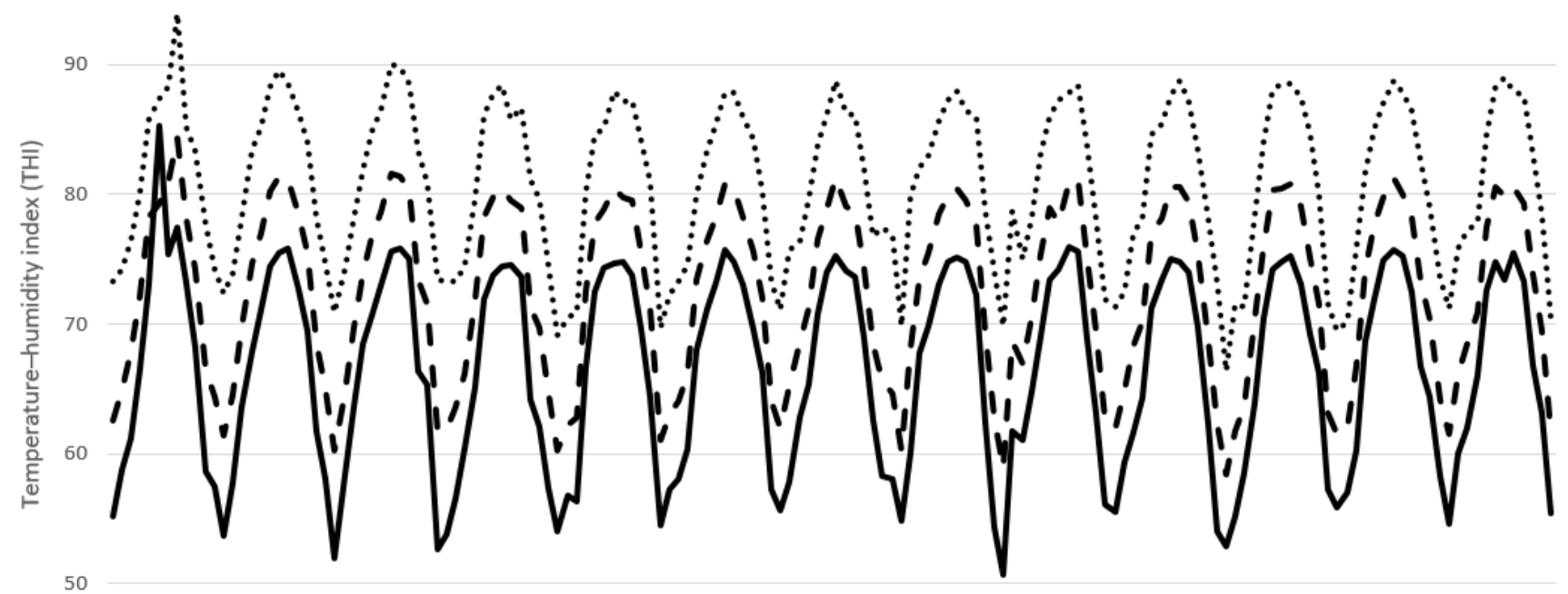

40

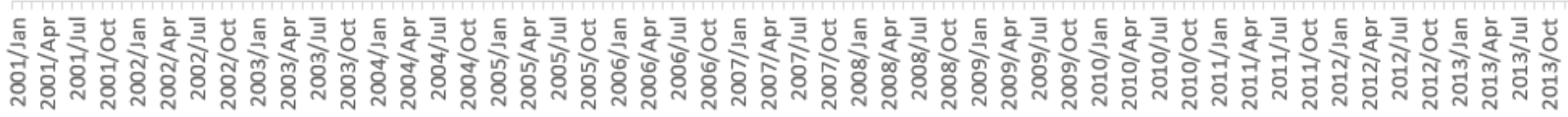

Data

Figure 1. Temporal trends of the evaluated monthly temperature-humidity index (THI mean, max, and min \%) during the studied period (from 2001 Jan to 2013 Oct) in central Taiwan.

275th and 280th days of gestation, inclusively. No significant difference regarding the gestation lengths was found across all cows of different parities.

\section{DISCUSSION}

In Quebec, the AFC occurs, on an average, at 27 months, whereas the target is between 23 months and 24.5 months to

Table 4. Mean temperature-humidity index (THI) thresholds associated with conception rates (CR) of heifers and multiparous cows

\begin{tabular}{lccccc}
\hline & \multicolumn{2}{c}{ Number of animals (N) } & & \multicolumn{2}{c}{ CR (\%) } \\
\cline { 2 - 3 } \cline { 5 - 6 } THI threshold & Heifers & $\begin{array}{c}\text { Multiparous } \\
\text { cows }\end{array}$ & & Heifers & $\begin{array}{c}\text { Multiparous } \\
\text { cows }\end{array}$ \\
\hline Mean THI $<60$ & 8 & 57 & & 61.26 & 52.21 \\
Mean THI 60-65 & 20 & 84 & & 58.41 & 51.15 \\
Mean THI 66-70 & 31 & 79 & & 56.15 & 49.13 \\
Mean THI 71-75 & 21 & 82 & & 57.72 & 46.82 \\
Mean THI 76-80 & 13 & 75 & & 54.42 & 42.26 \\
Mean THI > 80 & 12 & 60 & & 52.61 & 40.41 \\
Mean THI $\leq 72$ & 65 & 225 & & 59.14 & 50.68 \\
Mean THI $>72$ & 40 & 212 & & $55.12^{b}$ & $43.84^{\text {a }}$ \\
\hline
\end{tabular}

CR: conception rate (pregnancy per artificial insemination service).

$a, b$ Means with different superscripts in the same row differ at $p<0.05$. maximize herd profitability [9]. The data show that the mean age at the first service and AFC in Holstein heifers at the NCHU Experimental Animal Farm are 493.2 days and 813.5 days (27.1 months), which are similar to that in the United Kingdom and Quebec, respectively [7,9] (Table 7). The normal gestation period for cows is between 275 days and 280 days [10]. At the NCHU Experimental Animal Farm, the mean gestation lengths based on gestation data were 275.1 days and 277.9 days for Holstein heifers and cows, respectively. Furthermore, the gestation lengths were similar across all cows of different parities. Three cows at this farm went into early labor (parity 1 , on the 252 nd day, parity 2 on the 262th day, and parity 3 on the 262th day), which may have been due to heat stress or illness, judging by the observation records. CR is commonly used as a critical indicator to evaluate the reproductive efficiency of a dairy farm. Although high CRs were observed on cows in parity 6 and 7 with unknown reason, probably due to too few sample size of cows in the records, our results suggest that in general multiparous cows have lower CRs than heifers (Table 5). Multiparous cows have been reported to have lower reproductive abilities, in which their embryos may die in the early stages of pregnancy, and the implantation of embryos become more difficult after multiple pregnancies [11,12]. In addition, lower values of days open were found on cows in parity 6 and 7 , 
Table 5. Statistics of artificial insemination in Holstein cows with different parities

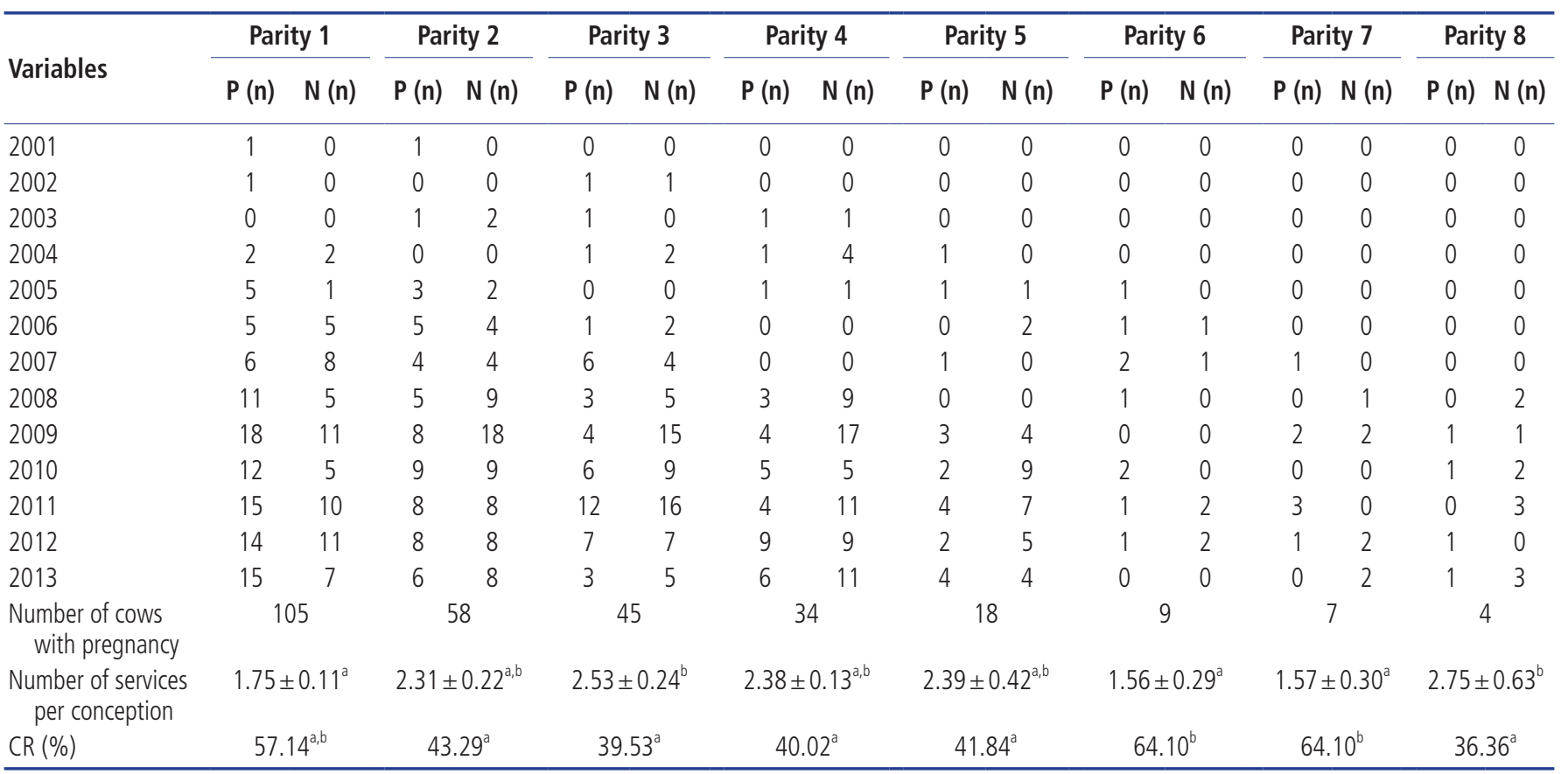

P, pregnancy; $N$, non-pregnancy; $n$, number of cows; $C R$, conception rate (pregnancy per artificial insemination service).

$a, b$ Means with different superscripts in the same row differ at $p<0.05$.

which supported to the results of CRs in the same parities (Table 6). A higher value of days open and the increased culling rate typically decreased the profitability of dairy herds. The studied farm had 100 pregnant heifers; 30 of them were sold and 70 were studied. The culling rate of cows was $27.14 \%$ for parity 1 to $2,15.69 \%$ for parity 2 to $3,34.88 \%$ for parity 3 to 4 , $50 \%$ for parity 4 to $5,42.86 \%$ for parity 5 to $6,25 \%$ for parity 6 to 7 , and $50 \%$ for parity 7 to 8 . Among these cows, parity 4 to 5 and 7 to 8 had the highest culling rates. After the fourth delivery, cows were culled due to reproductive disorders (37.66\%) occurred during lactation or pregnancy or due to illnesses such as mastitis (18.18\%), or other health problems including lameness, milk fever, abomasum dislocation, bovine ephemeral fever, tuberculosis, or death (44.16\%). Our results suggest that the reproduction-related parameters should be weighted in the culling criteria for multiparous cows above 4 parties in Taiwan.

THI is used for assessing thermal stress, and high-producing dairy cows are adversely affected when THI exceeds 72 $[13,14]$. In the present study, THI was significantly affected by the season, with a monthly variation ranging between 60 and 80 . Taiwan has an island climate, with the sea breeze blow-

Table 6. Variations in the number of days open of Holstein cows with different parities

\begin{tabular}{lccccccc}
\hline \multicolumn{1}{c}{ Variables } & Parity $\mathbf{1}$ to $\mathbf{2}$ & Parity $\mathbf{2}$ to $\mathbf{3}$ & Parity $\mathbf{3}$ to $\mathbf{4}$ & Parity $\mathbf{4}$ to $\mathbf{5}$ & Parity $\mathbf{5}$ to $\mathbf{6}$ & Parity $\mathbf{6}$ to $\mathbf{7}$ & Parity $\mathbf{7}$ to $\mathbf{8}$ \\
\hline Number of cows & 51 & 43 & 27 & 14 & 8 & 6 & 3 \\
Days open (min, max) & $151 \pm 15^{\mathrm{a}}$ & $182 \pm 17^{\mathrm{a}, \mathrm{b}}$ & $156 \pm 28^{\mathrm{a}}$ & $178 \pm 40^{\mathrm{a}, \mathrm{b}}$ & $157 \pm 47^{\mathrm{a}}$ & $158 \pm 32^{\mathrm{a}}$ & $219 \pm 31^{\mathrm{b}}$ \\
& $(52,604)$ & $(39,498)$ & $(49,665)$ & $(53,558)$ & $(49,414)$ & $(59,302)$ & $(165,273)$ \\
\hline
\end{tabular}

a,b Means with different superscripts in the same row differ at $p<0.05$.

Table 7. Gestation length of Holstein cows with different parities

\begin{tabular}{lcccccccc}
\hline Variables & Parity 1) & Parity 2 & Parity 3 & Parity 4 & Parity 5 & Parity $\mathbf{6}$ & Parity $\mathbf{7}$ & Parity 8 \\
\hline Number of cows & 70 & 51 & 43 & 28 & 14 & 8 & 6 & 3 \\
Gestation length & & & & & & & \\
Mean (d) & $275.1 \pm 6.5$ & $277.8 \pm 6.28$ & $276.8 \pm 5.4$ & $279.1 \pm 6.4$ & $275.4 \pm 6.2$ & $277.4 \pm 4.0$ & $278.2 \pm 5.0$ & $280.7 \pm 2.9$ \\
Min (d) & 252 & 263 & 260 & 270 & 262 & 273 & 271 & 279 \\
Max (d) & 294 & 297 & 289 & 304 & 283 & 285 & 286 \\
\hline
\end{tabular}

${ }^{1)}$ The mean age at the first service and age at first calving in Holstein heifers are 493.2 days and 813.5 days (27.1 months), respectively. 
ing inland in the evening during summer; this carries away the heat built up in the animal housing, and thus reduces the extent of cows exposed to heat stress in the evening [15]. Therefore, while CR appeared to be lower in cows under heat stress than in those not under heat stress, it did not reach a significant difference. Although CR showed no significant difference between both $\mathrm{THI}>72$ and $\mathrm{THI} \leq 72$ ambient conditions in heifers or multiparous cows, there is a significant difference between heifers and multiparous cows when THI $>72$. Ferreira et al [11] suggested that cow oocytes are more sensitive to heat stress during the hot season. Heifers and cows showed a similar number of recovered and viable oocytes during winter, but during summer the cow oocyte numbers significantly decreased $[12,16]$. In the present study, lactating cows have lower CR during summer and fall than that during winter and spring. However, during spring, summer, fall, and winter, CRs were similar in heifers. Because heat stress during summer and fall resulted in a decreased CR of multiparous cows in the current study, lactating cows are suggested to be bred in winter and spring from the start of the seasonal breeding program, whereas the heifer can be bred in all seasons under the subtropical climate in Taiwan.

In Taiwan, the heat stress is a potential threat that induces impaired reproductive performance such as syndromes of puerperal metritis (PM) and retained placenta (RP) in dairy cows [17]. Additional reproductive strategies are needed to counteract the adverse effect of heat stress on fertility during summer and fall. To improve the reproductive efficiency of dairy cows with PM/RP, we previously reported an effective, two-step treatment strategy using combined medical manipulation for regulating uterine involution and ovarian function in such cows, which enhanced reproductive efficiency via controlling uterine infections well and, thereby, facilitating an early resumption of ovarian activity of dairy herds [17]. In addition, from the beginning of the summer till the end of fall, keeping lactating cows cool can provide a good return on investment as it makes cows more comfortable, thereby, making them more productive in subtropical climates. Because the price of raw milk is relatively higher in summer than that in winter, regardless of the effect of heat stress, many dairy farmers in Taiwan prefer to breed cows in the early summer season in order to obtain higher milk yields in hot seasons of the next year. The suggested breeding strategy in the study allows farmers to use heifers to maintain a higher production of raw milk in summer.

\section{IMPLICATIONS}

In conclusion, our data shows that at $\mathrm{THI}$ of $>72$ and during the hot season (from June to November), CRs were significantly higher in heifers than in multiparous cows, although no significant differences were observed in the number of days open or gestation length on a dairy farm in a subtropical region in Taiwan. The contributions of physiological condition and genetic background will need to be included for further characterization of the relationship between stress response and reproductive performance in subtropical regions in Taiwan.

\section{CONFLICT OF INTEREST}

We certify that there is no conflict of interest with any financial organization regarding the material discussed in the manuscript.

\section{ACKNOWLEDGMENTS}

The authors are thankful to Professor Peng-Wen (Jacky) Chan for veterinary care and all facilities provided by Experimental Animal Farm, National Chung Hsing University to complete this project.

\section{REFERENCES}

1. Rensis FDI, Garcia-Ispierto I, López-Gatius F. Seasonal heat stress: clinical implications and hormone treatments for the fertility of dairy cows. Theriogenology 2015;84:659-66.

2. Kadzere CT, Murphy MR, Silanikove N, Maltz E. Heat stress in lactating dairy cows: a review. Livest Prod Sci 2002;77:59-91.

3. Hansen PJ, Drost MR, Rivera RM, et al. Adverse impact of heat stress on embryo production: causes and strategies for mitigation. Theriogenology 2001;55:91-103.

4. Sartori R, Sartor-Bergfelt R, Mertens SA, et al. Fertilization and early embryonic development in heifers and lactating cows in summer and lactating and dry cows in winter. J Dairy Sci 2002;85:2803-12.

5. Schüller LK, Burfeind O, Heuwieser W. Impact of heat stress on conception rate of dairy cows in the moderate climate considering different temperature-humidity index thresholds, periods relative to breeding, and heat load indices. Theriogenology 2014;81:1050-7.

6. Allen JD, Hall LW, Collier RJ, Smith JF. Effect of core body temperature, time of day, and climate conditions on behavioral patterns of lactating dairy cows experiencing mild to moderate heat stress. J Dairy Sci 2015;98:118-27.

7. Cooke JS, Cheng Z, Bourne NE, Wathes DC. Association between growth rates, age at first calving and subsequent fertility, milk production and survival in Holstein-Friesian heifers. Open J Anim Sci 2013;3:1-12.

8. Zavadilová L., Štípková M. Effect of age at first calving on longevity and fertility traits for Holstein cattle. Czech J Anim Sci 2013;58:47-57.

9. Duplessis M, Cue RI, Santschi DE, Lefebvre DM, Lacroix R. Weight, height, and relative-reliability indicators as a management tool for reducing age at first breeding and calving of 
dairy heifers. J Dairy Sci 2015;98:2063-73.

10. Norman HD, Wright JR, Kuhn MT, et al. Genetic and environmental factors that affect gestation length in dairy cattle. J Dairy Sci 2009;92:2259-69.

11. Ferreira RM, Ayres H, Chiaratti MR, et al. The low fertility of repeat-breeder cows during summer heat stress is related to a low oocyte competence to develop into blastocysts. J Dairy Sci 2011;94:2383-92.

12. Rocha A, Randel RD, Broussard JR, et al. High environmental temperature and humidity decrease oocyte quality in Bos taurus but not in Bos indicus cows. Theriogenology 1998;49:657-65.

13. Armstrong DV. Heat stress interaction with shade and cooling. J Dairy Sci 1994;77:2044-50.

14. Berman A. Extending the potential of evaporative cooling for heat-stress relief. J Dairy Sci 2006;89: 3817-25.

15. Shiao TF, Chen JC, Yang DW, et al. Feasibility assessment of a tunnel-ventilated, water-padded barn on alleviation of heat stress for lactating Holstein cows in a humid area. J Dairy Sci 2011; 94:5393-404.

16. Morton JM, Tranter WP, Mayer DG, Jonsson NN. Effects of environmental heat on conception rates in lactating dairy cows: Critical periods of exposure. J Dairy Sci 2007;90:2271-8.

17. Liu WB, Chung ST, Shyu CL, et al. Strategy for the treatment of puerperal metritis and improvement of reproductive efficiency in cows with retained placenta. Acta Vet Hung 2011;59: 247-56.

18. NRC. Nutrient requirements of dairy cattle. 7th rev. ed. Washington, DC, USA: National Academy Press; 2001. 